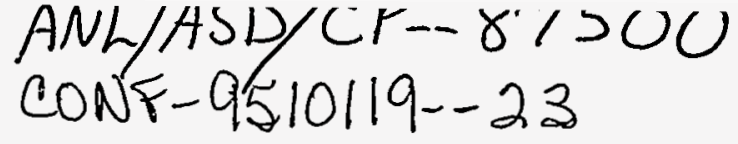

\title{
Performance of the Beam Position Monitor for the Advanced Photon Source
}

\author{
Y. Chung and E. Kahana \\ Accelerator Systems Division, Advanced Photon Source, Argonne National Laboratory, Argonne, IL 60439
}

(Presented on October 19, 1995)

Performance measurement and analysis of the Advanced Photon Source (APS) beam position monitor (BPM) electronics are reported. The results indicate a BPM resolution of $0.16 \mu \mathrm{m} \cdot \mathrm{mA} / \sqrt{\mathrm{Hz}}$ in terms of the single-bunch current and BPM bandwidth. For the miniature insertion device (ID) BPM, the result was $0.1 \mu \mathrm{m} \cdot \mathrm{mA} / \sqrt{\mathrm{Hz}}$. The improvement is due to the 3.6 times higher position sensitivity (in the vertical plane), which is partially canceled by the lower button signal by a factor of 2.3. The minimum single-bunch current required was roughly $0.03 \mathrm{~mA}$. The long-term drift of the

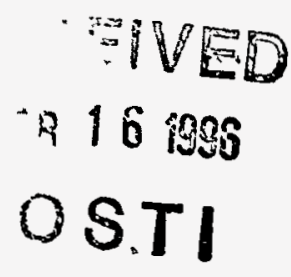
BPM electronics independent of the actual beam motion was measured at $2 \mu \mathrm{m} / \mathrm{hr}$, which settled after approximately 1.5 hours. This drift can be attributed mainly to the temperature effect. Implications of the BPM resolution limit on the global and local orbit feedback systems for the APS storage ring will also be discussed.

\section{INTRODUCTION}

Measurement of the particle beam position in accelerators is an essential part of the beam diagnostics system, and the beam position monitors (BPMs) provide the basic diagnostics tool for commissioning and operation of accelerators. One of the primary applications of the BPMs is the stabilization of the particle and $X$-ray beam positions through feedback. ${ }^{1,2}$ The specification of the required BPM resolution for beam position feedback in the Advanced Photon Source (APS) storage ring is listed in Table I.

TABLE I: Specification of the orbit feedback systems.

\begin{tabular}{|c|ccc|}
\hline $\begin{array}{c}\text { Orbit measurement } \\
\text { device }\end{array}$ & $\begin{array}{c}\text { All of the ff } \\
\text { BPMs }\end{array}$ & $\begin{array}{c}\text { Global AC } \text { BPMs } \\
\text { (1/sector) }\end{array}$ & $\begin{array}{c}\text { Local } \\
\text { XPMs } \\
\text { X-ray } \\
\text { BPMs }\end{array}$ \\
\hline Correctors & $\begin{array}{c}\text { All } \\
\text { correctors }\end{array}$ & $\begin{array}{c}\text { Subset of } \\
\text { correctors }\end{array}$ & $\begin{array}{c}\text { Local } \\
\text { bump }\end{array}$ \\
\hline $\begin{array}{c}\text { Specified orbit } \\
\text { measurement } \\
\text { resolution }\end{array}$ & $25 \mu \mathrm{m}$ & $25 \mu \mathrm{m}$ & $1 \mu \mathrm{m}$ \\
\hline $\begin{array}{c}\text { Achievable } \\
\text { resolution }\end{array}$ & $5 \mu \mathrm{m}$ & $5 \mu \mathrm{m}$ & $1 \mu \mathrm{m}$ \\
\hline $\begin{array}{c}\text { Required range of } \\
\text { correction }\end{array}$ & $\pm 20 \mathrm{~mm}$ & $\pm 500 \mu \mathrm{m}$ & $\pm 100 \mu \mathrm{m}$ \\
\hline
\end{tabular}

The BPMs in the storage ring (SR) and injector synchrotron (IS) of the APS have four button-type pickups mounted directly on an elliptically shaped vacuum chamber. ${ }^{3}$ The button size and the sensitivity of these BPMs are listed in Table II. The theoretical calculation was done analytically with an elliptic vacuum chamber with no photon exit channel, ${ }^{+}$which shows significant difference from the measured value in the case of the insertion device (ID) BPM due to the asymmetry in geometry.

In this paper, we will describe measurements of resolution and long-term drift of the APS BPM electronics using the charged particle beam. Design, development, and

\section{DISTRIBUTION OF THIS DOCUMENT IS UNLIMITED/AS}

preliminary tests of the BPM electronics are described in Refs. 5, 6, and 7.

TABLE I: Parameters for the APS BPMs in the storage ring (SR), injector synchrotron (IS), and insertion devices with $12-\mathrm{mm}$ and 8-mm gap.

\begin{tabular}{|l|c|c|c|c|}
\hline & SR & IS & $\begin{array}{c}\text { D } \\
12 \mathrm{~mm}\end{array}$ & $\begin{array}{c}\text { D } \\
8 \mathrm{~mm}\end{array}$ \\
\hline Button radius (cm) & 0.5 & 0.5 & 0.2 & 0.2 \\
$S_{x}\left(\mathrm{~cm}^{-1}\right)$ & 0.57 & 0.70 & 2.08 & 3.44 \\
$S_{x}^{*}\left(\mathrm{~cm}^{-1}\right)$ & 0.58 & 0.70 & 1.63 & - \\
$S_{y}\left(\mathrm{~cm}^{-1}\right)$ & 0.53 & 0.58 & 1.51 & 1.47 \\
$S_{y}^{*}\left(\mathrm{~cm}^{-1}\right)$ & 0.55 & 0.57 & 1.54 & - \\
\hline
\end{tabular}

\section{BPM OPERATION AND ERROR ANALYSIS}

The BPM samples the beam position $N$ consecutive times with the time interval $\Delta t$ with 12 -bit resolution. Due to the time delay in the processing electronics, the minimum $\Delta t$ is roughly $1.2 \mu \mathrm{s}$. With the $3.68-\mu \mathrm{s}$ revolution time, there can be at most three samples per revolution. If we let $x(t)$ be the actual beam position at time $t$ and if we let $t_{n}$ be the starting time of sampling, the averaged beam position $x_{n}$ is then given by

$$
x_{n}=\frac{1}{N} \sum_{k=0}^{N-1}\left(x\left(t_{n}+k \Delta t\right)+\delta x_{n, k}\right)
$$

where $\delta x_{n, k}$ is the BPM error assumed to be randomly independent of $n$ and $k$.

The BPMs can be put in one of three modes: $x$-only, $y$ only, and $x y$-toggling. In the $x$-only mode, the BPM processing electronics sample only the $x$ coordinate of the beam position, and only the $y$ coordinate is sampled in the $y$ only mode. In the $x y$-toggling mode. both the $x$ and $y$ coordinates are sampled but only at half the rate of the $x$-only or $y$-only modes for each plane. Therefore, in the xy-toggling mode, $\Delta t$ is twice as large as the $x$-only or $y$-only modes.

Suppose the beam motion has the harmonic time dependence as given by 


$$
x(t)=a e^{-i \Omega t},
$$

where $\Omega$ is the frequency of oscillation and $a$ is a complex number representing the amplitude and phase. Inserting Eq. (2) into Eq. (1), we obtain

$$
x_{n}=\frac{2 a}{N \Omega \Delta t} \exp \left(-i \Omega t_{n}\right) \sin \left(\frac{1}{2} N \Omega \Delta t\right)+\frac{1}{N} \sum_{k=0}^{N-1} \delta x_{n, k},
$$

where a constant complex factor was absorbed into $a$ and it is assumed that $\Omega \Delta t \ll 1$. The rms beam position measurement error would then be given by

$$
\Delta x^{2} \leq \Delta x_{b}^{2}+\frac{\left(\delta x_{e}\left(I_{b}\right)\right)^{2}}{N},
$$

where $\Delta x_{b}=|a| / \sqrt{2}$ is the rms beam motion and $\delta x_{e}\left(I_{b}\right)$ is a measure of the BPM resolution as a function of the beam current $I_{b}$.

In this work, we want to measure the second term in Eq. (4) apart from the actual beam motion. Since the two terms are added in quadrature, measurements would be more accurate if the second term dominates, e.g., by using small $N$ and by reducing the beam current as much as possible. If this condition is satisfied, the BPM electronics resolution $\Delta x_{e}$ would be given by

$$
\Delta x_{e}=\frac{\delta x_{e}\left(I_{b}\right)}{\sqrt{N}} .
$$

The unwanted contribution $\Delta x_{b}$ can be further reduced by cross-connecting the cables attached to the BPM buttons and putting the processing electronics in $x$-only or $y$-only mode. For example, if the top or bottom two cables are crossed, the first-order BPM response would be negligible in the $x$-only mode. Another method of canceling the BPM response is to use a pair of power divider/combiners. The former method was used in this work.

\section{MEASUREMENTS}

The APS storage ring has 40 sectors. For this work, the BPMs in sectors $1,2,3,6,7$, and 9 were used as shown in Table III. Some BPMs that had crossed connections were picked from different sectors to minimize the impact on operation. For sector 7, all of the BPMs were used under normal configuration. The measurement setup and data collection were done through the APS control system.

TABLE III: BPM configuration

\begin{tabular}{|c|l|}
\hline BPMs & \multicolumn{1}{|c|}{ Configuration } \\
\hline S1B:P1, S2A:P1 & ID BPMs. Normal connection \\
S3A:P1, S6B:P1 & Top buttons crossed \\
S7(A,B):Pn & Normal \\
S9A:P1, S9B:P1 & Inboard buttons crossed \\
\hline
\end{tabular}

Figure 1 shows the results of measurements on the BPM measurement error as a function of $N$ for the single-bunch current $I_{b}=0.22 \mathrm{~mA}$. The error decreases as $1 / \sqrt{N}$ as shown in Eq. (5). As the beam current increases, this relation becomes less apparent, and at $I_{b} \sim 7 \mathrm{~mA}$, the error on S7:x was virtually independent of $N$.

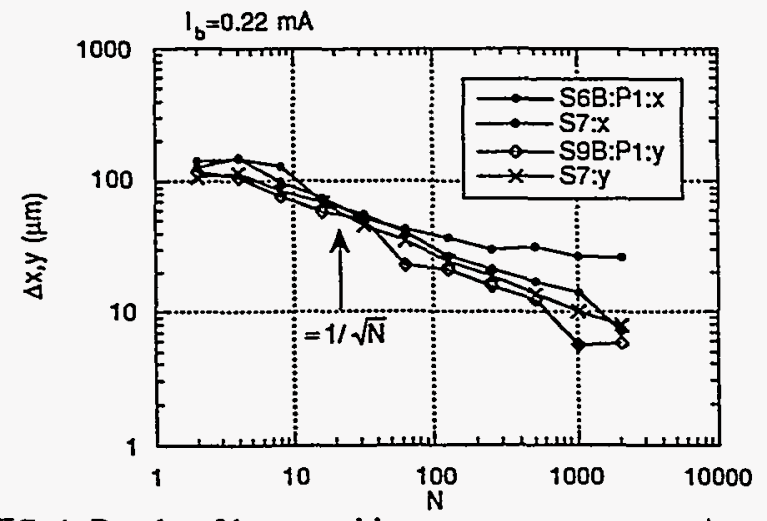

FIG. 1. Results of beam position measurement errors $\Delta x$ and $\Delta y$ as a function of $N$ for the single-bunch beam current $I_{b}=0.22 \mathrm{~mA}$.

The dependence of the beam position measurement error on the beam current $I_{b}$ is shown in Fig. 2. For the BPMs with crossed connections, the error decreases as $1 / I_{b}$. For the normal BPMs (S7:x and S7:y), the error decreases initially but approaches asymptotically about $30 \mu \mathrm{m}$ for $x$ and $15 \mu \mathrm{m}$ for $y$ due to the contribution from the actual beam motion. For miniature ID BPMs, the intensity is decreased by roughly 2.3 , but the sensitivity is increased by $2.7\left(S_{x}\right)$ and $3.6\left(S_{y}\right)$, respectively. Therefore, we obtain from the results shown in Figs. 2 and 3

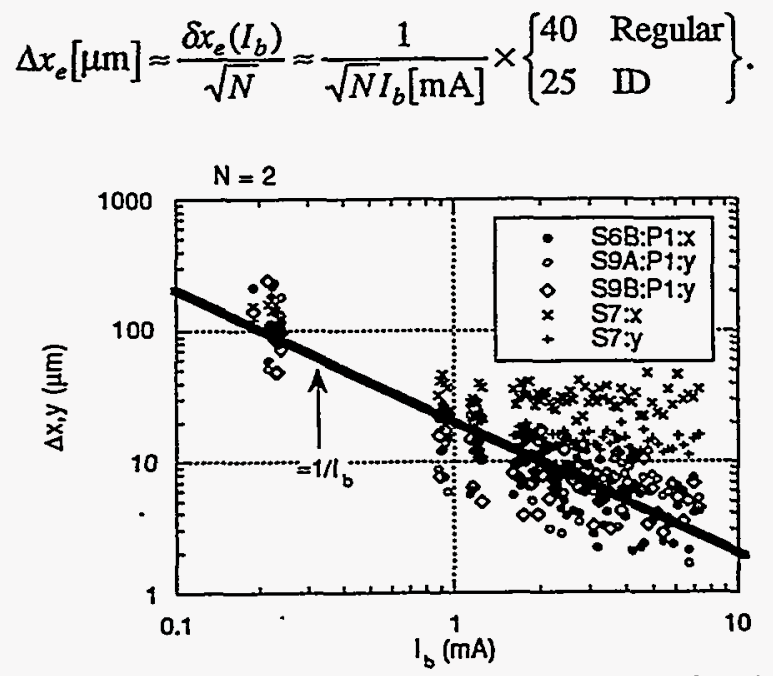

FIG. 2. The beam position measurement error as a function of the single bunch current $I_{b}$ for $N=2$.

Let us now convert Eq. (6) using the $\mu \mathrm{m} \cdot \mathrm{mA} / \sqrt{\mathrm{Hz}}$ unit. The frequency response of the simple averager on the BPM can be written as

$$
\mid H\left(f X \mid=\frac{1}{N} \frac{\sin \left(N \pi f / F_{s}\right)}{\sin \left(\pi f / F_{s}\right)},\right.
$$

where $F_{s}$ is the sampling frequency. In the $x y$-toggling mode with a single bunch, it is equal to $136 \mathrm{kHz}$ for the APS storage ring. Then, the bandwidth $(-3 \mathrm{~dB})$ corresponds to approximately $N f=1.39 F_{s} / \pi \approx 60 \mathrm{kHz}$. From Eq. (6), the BPM resolution is 


$$
\Delta x_{e}[\mu \mathrm{m}]=\frac{\sqrt{f_{\mathrm{BPM}}[\mathrm{Hz}]}}{I_{b}[\mathrm{~mA}]} \times\left\{\begin{array}{ll}
0.16 & \text { Regular } \\
0.1 & \mathrm{ID}
\end{array}\right\} .
$$

where $f_{\mathrm{BPM}}$ is the BPM bandwidth.

Since the BPM resolution is inversely proportional to $\sqrt{F_{s}}$, it can be improved by increasing the sampling frequency $F_{s}$. The minimum sampling time by the processing electronics is $1.2 \mu \mathrm{s}$, and therefore, with the 3.68us revolution time in the APS storage ring, there can be as many as three triggers per turn if the bunches are grouped into three equally spaced clusters.

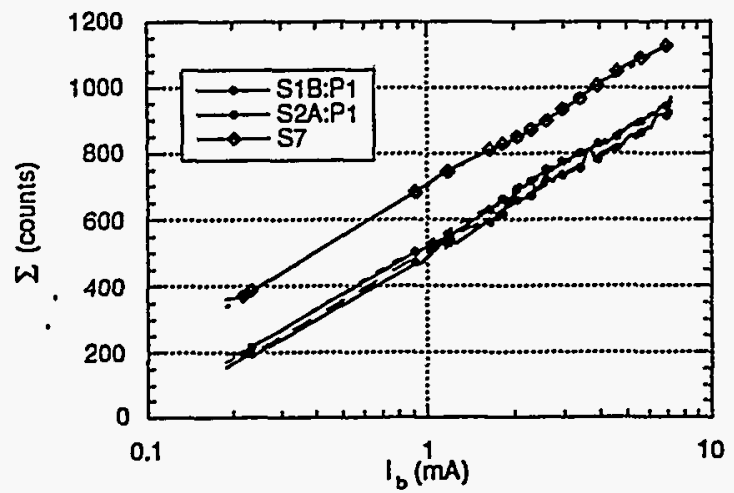

FIG. 3. The BPM button signal sensitivity $\Sigma$ as a function of the single-bunch beam current $I_{b}$.

Measurement of the BPM button signal sensitivity $\Sigma$ as a function of the single bunch current is shown in Fig. 3. The logarithmic fit to the data gives

$$
\Sigma[\text { Counts }] \approx \begin{cases}700+500 \log \left(I_{b}[\mathrm{~mA}]\right), & \text { Regular } \\ 520+490 \log \left(I_{b}[\mathrm{~mA}]\right), & \text { ID }\end{cases}
$$

As a comparison, we made separate measurements in the laboratory using a $C W$ rf source $(-10 \mathrm{dBm}$ with $40 \mathrm{~dB}$ amplifier) feeding a 1-to-4 divider connected to a filtercomparator. The result indicated $12 \mu \mathrm{m}$ of resolution with $N$ $=2$. Average $\Sigma$ was 930 counts, which is equivalent to 2.9 $\mathrm{mA}$ according to Eq. (9). This is in good agreement with Eq. (6), which gives $10 \mu \mathrm{m}$.

The long-term drift of the BPM electronics was measured on the ESRF storage ring using the 1-to-4 divider to balance the signal and thus cancel the beam position sensitivity. ${ }^{8}$ The stored beam current was $I_{b}=102.5 \mathrm{~mA}$ with $1 / 3$-fill. In order to reduce the short-term fluctuation, the highest number of averages $N=2048$ was used. The result indicates a longterm drift of about $2 \mu \mathrm{m} / \mathrm{hr}$.

\section{SUMMARY AND DISCUSSION}

In this work, we described measurements of resolution and long-term drift of the Advanced Photon Source beam position monitor electronics using the charged particle beam.

BPM resolution measurements were done using a single bunch on the regular storage ring BPMs and the miniature insertion device BPMs. Different beam currents and BPM bandwidths were used to estimate the BPM resolution and contribution from the actual beam motion. The results indicate that the resolution is proportional to $\sqrt{f_{\mathrm{BPM}}} / I_{b}$, where $f_{\mathrm{BPM}}$ is the BPM bandwidth and $l_{b}$ is the single-bunch beam current. The constant of proportionality is 0.16 for the regular storage ring BPM and 0.1 for the miniature ID BPM in units of $\mu \mathrm{m} \cdot \mathrm{mA} / \sqrt{\mathrm{Hz}}$. These results are in good agreement with separate laboratory measurements conducted with a CW rf source.

The long-term drift measurement on the ESRF storage ring with the stored beam current of $102.5 \mathrm{~mA}$ with $1 / 3$-fill indicates $2 \mu \mathrm{m} / \mathrm{hr}$. This drift can be attributed mainly to the temperature effect.

In the APS storage ring, the if BPMs will be used for global and local beam position feedback to stabilize the particle and $x$-ray beams. The correction bandwidth is expected to be approximately $100 \mathrm{~Hz}$ with projected sampling frequency of $4 \mathrm{kHz}$. Within this bandwidth and with the single-bunch current of $1 \mathrm{~mA}$, the resolution would be better than $0.16 \times \sqrt{100}=1.6 \mu \mathrm{m}$ for regular BPMs and $1 \mu \mathrm{m}$ for miniature ID BPMs. Beam position perturbation larger than this resolution will be corrected by feedback.

\section{ACKNOWLEDGMENT}

Thanks also go to J. Galayda, G. Decker, and A. Lumpkin for their continued support and interest. This work was supported by the U.S. Department of Energy, Office of Basic Energy Sciences, under Contract No. W-31-109-ENG38.

${ }^{1}$ Y. Chung, "A Unified Approach to Global and Local Beam Position Feedback," Proceedings of the 4th European Particle Accelerator Conference, London, 1994.

${ }^{2} Y$. Chung, "Beam Position Feedback System for the Advanced Photon Source," Proceedings of the 5th Beam Instrumentation Workshop, Santa Fe, New Mexico, 1993.

${ }^{3}$ G. Decker and Y. Chung, "Progress on the Development of APS Beam Position Monitoring System," Proceedings of IEEE Particle Accelerator Conference, San Francisco, 1991, p. 2545.

${ }^{4} Y$. Chung, "Theoretical Studies on the Beam Position Measurement with Button-type Pickups in APS," Proceedings of IEEE Particle Accelerator Conference, San Francisco, 1991, p. 1121.

$5 \mathrm{E}$. Kahana, "Design of the Beam Position Monitor Electronics for the APS Diagnostics," Proceedings of the 3rd Beam Instrumentation Workshop, Newport News, Virginia, 1991, p.235.

${ }^{6} \mathrm{E}$. Kahana and Y. Chung, "Test Results of a Monopulse Beam Position Monitor for the Advanced Photon Source," Proceedings of the 4th Beam Instrumentation Workshop, Berkeley, California, 1992, p. 271.

${ }^{7}$ E. Kahana, Y. Chung, A.J. Votaw and F. Lenkszus, "Configuration and Test of the APS Storage Ring Beam Position Monitor Electronics," Proceedings of the 5 th Beam Instrumentation Workshop, Santa Fe, New Mexico, 1993.

${ }^{8} \mathrm{Y}$. Chung and E. Kahana, "Resolution and Drift Measurements on the Advanced Photon Source Beam Position Monitor," Proceedings of the 6th Beam Instrumentation Workshop. Vancouver, B.C., Canada. 1994. 


\section{DISCLAIMER}

This report was prepared as an account of work sponsored by an agency of the United States Government. Neither the United States Government nor any agency thereof, nor any of their employees, makes any warranty, express or implied, or assumes any legal liability or responsibility for the accuracy, completeness, or usefulness of any information, apparatus, product, or process disclosed, or represents that its use would not infringe privately owned rights. Reference herein to any specific commercial product, process, or service by trade name, trademark, manufacturer, or otherwise does not necessarily constitute or imply its endorsement, recommendation, or favoring by the United States Government or any agency thereof. The views and opinions of authors expressed herein do not necessarily state or reflect those of the United States Government or any agency thereof. 